Gut, 1986, 27, 418-422

\title{
Histamine and duodenal ulcer: effect of omeprazole on gastric histamine in patients with duodenal ulcer
}

\author{
W K MAN, J N THOMPSON, J H BARON, AND J SPENCER \\ From the Department of Surgery, Royal Postgraduate Medical School, Hammersmith Hospital, London
}

SUMMARY Gastric mucosal concentrations of histamine and of its metabolic enzyme, histamine methyltransferase activity, were measured in patients with duodenal ulcer disease and patients with an apparently normal stomach and duodenum. Patients with duodenal ulcer had significantly less $(\mathrm{p}<0 \cdot 05)$ mucosal histamine (median $204 \mathrm{nmol} / \mathrm{g}$ ) than control subjects (median $252 \mathrm{nmol} / \mathrm{g}$ ). There was no significant difference between the two groups in their histamine methyltransferase activity values. Omeprazole therapy did not significantly change mucosal histamine $(+23 \%)$, histamine methyltransferase activity $(+5 \%)$, histamine release before $(+5 \%)$ or during $(+7 \%)$ pentagastrin infusion. It significantly decreased acid secretion during pentagastrin stimulation (median $-73 \%, \mathrm{p}<0.001$ ). Omeprazole, like cimetidine, does not stop histamine release during pentagastrin stimulation.

Histamine may be involved in the pathogenesis of human peptic ulcer. Patients with duodenal ulcer have less gastric mucosal histamine and lower activity of the metabolic enzyme, histamine methyltransferase, than normal control subjects. After treatment with cimetidine, ${ }^{1}$ or after selective gastric vagotomy, ${ }^{23}$ however, mucosal histamine and histamine methyltransferase activity rise above normal control values. The depletion of the endogenous mucosal histamine stores is associated with gastric hypersecretion, which is a prominent feature of duodenal ulcer disease. ${ }^{12}$ After vagotomy, increase in mucosal histamine parallels the reduction in peak acid output. ${ }^{4}$ It is not known, however, whether the mucosal changes associated with cimetidine therapy or vagotomy are direct effects, or simply because of reducing acid secretion.

Like cimetidine, omeprazole is an effective inhibitor of gastric acid secretion and increases the rate of healing of duodenal ulcer. Cimetidine blocks the $\mathrm{H}_{2}$ receptor but omeprazole inhibits the $\mathrm{H}^{+} \mathrm{K}^{+}$ATPase of the gastric proton pump on the parietal cell membrane. 5

We have investigated in patients with duodenal ulcer disease the effects of omeprazole on: (a) gastric mucosal histamine and histamine methyl-

Address for correspondence: Mr J Spencer, FRCS, Department of Surgery, Royal Postgraduate Medical School, Hammersmith Hospital, London W12 OHS.

Received for publication 7 May 1985 transferase activity; (b) gastric acid and histamine secretion during pentagastrin stimulation.

\section{Methods}

PATIENTS

Ten patients in whom gastroduodenoscopy revealed no visible abnormality and 14 patients with duodenal ulcer confirmed at endoscopy were included in this part of the present study. Gastric mucosal biopsies were obtained at gastroscopy and assayed for histamine and histamine methyltransferase activity. The patients had received no histamine 2 antagonists for at least a week before entering the study.

OMEPRAZOLE TRIAL

Eight out of the 14 patients with duodenal ulcer were endoscoped 24 hours before a pentagastrin stimulated gastric acid secretion test. They were given a course of omeprazole lasting for four weeks; four received $20 \mathrm{mg}$ and the other four $40 \mathrm{mg}$ daily as part of a prospective randomised controlled trial reported elsewhere. ${ }^{6}$ Antacids were consumed according to need during this period of treatment. Endoscopic biopsies and secretory assessments were then repeated. The biopsies were assayed for histamine and histamine methyltransferase activity. Gastric aspirates were assayed for acid and histamine. In addition, three other patients underwent acid secretion tests before and after a course of omeprazole; one received $20 \mathrm{mg}$ and two $40 \mathrm{mg}$ 
daily. Secretory assessments were carried out on these patients, but no biopsies were taken.

\section{HISTAMINE IN GASTRIC MUCOSA}

Three endoscopic biopsies, 5-10 mg each, were taken from the anterior gastric wall $45 \mathrm{~cm}$ from the mouth. They were stored and frozen immediately until analysis. The biopsy was homogenised in 0.5 $\mathrm{ml}$ ice cold $0.01 \mathrm{M}$ sodium phosphate, $\mathrm{pH} \mathrm{7.9,}$ containing $0.1 \%(\mathrm{w} / \mathrm{v})$ Triton $\mathrm{X}-100$. The homogeniser was washed through with two portions of $0.25 \mathrm{ml}$ cold buffer.

\section{HISTAMINE ASSAY}

Histamine assay was based on the fluorometric method of Troidl $e t a l^{2}$ and has been described in detail. $^{7}$

\section{Histamine methyltransferase assay}

Histamine methyltransferase activity was assayed by a modification of the procedure of Taylor and Snyder. ${ }^{8}$ Protein was determined on $50 \mu$ l of the homogenate supernatant by the method of Lowry et al. ${ }^{9}$ Histamine methyltransferase activity was expressed as pmol $\mathrm{N}^{\mathrm{t}}$-methyl histamine formed/mg protein/min incubation. The histamine methyltransferase assay appeared to be specific. The reaction was directly proportional to the amount of homogenate protein and to incubation time (Fig. 1). Aminoguanidine, an inhibitor of the oxidative deamination of histamine, did not facilitate the reaction under incubation conditions and was therefore not included in the reaction mixture. ${ }^{3} \mathrm{H}-\mathrm{N}^{\mathrm{t}}$ methylhistamine and ${ }^{14} \mathrm{C}-\mathrm{N}^{\mathrm{t}}$-methylhistamine were prepared by enzymatic formation. Recoveries through the histamine methyltransferase assay procedure were both $44 \%$ (mean values of two determinations). With each assay ${ }^{3} \mathrm{H}-\mathrm{N}^{\mathrm{t}}$-methylhistamine was used as internal standard and the recovery (39-47\%) was used to calculate the histamine methyltransferase activity of the test sample. All assays were undertaken on material from three biopsies, and results expressed as the mean of the three.

ACID AND HISTAMINE IN GASTRIC ASPIRATE

Acid and histamine were assayed by procedures published in detail previously. ${ }^{3}$ Gastric acid was measured by titration to $\mathrm{pH} 7.0$ using an automatic titrimeter (Copenhagen). Gastric histamine was assayed fluorometrically.

The gastric acid and histamine output were corrected for gastroduodenal loss by using an inert non-absorbable marker (phenol red) to perfuse the stomach, and duodenogastric reflux by measurement of sodium ions in the gastric aspirate.

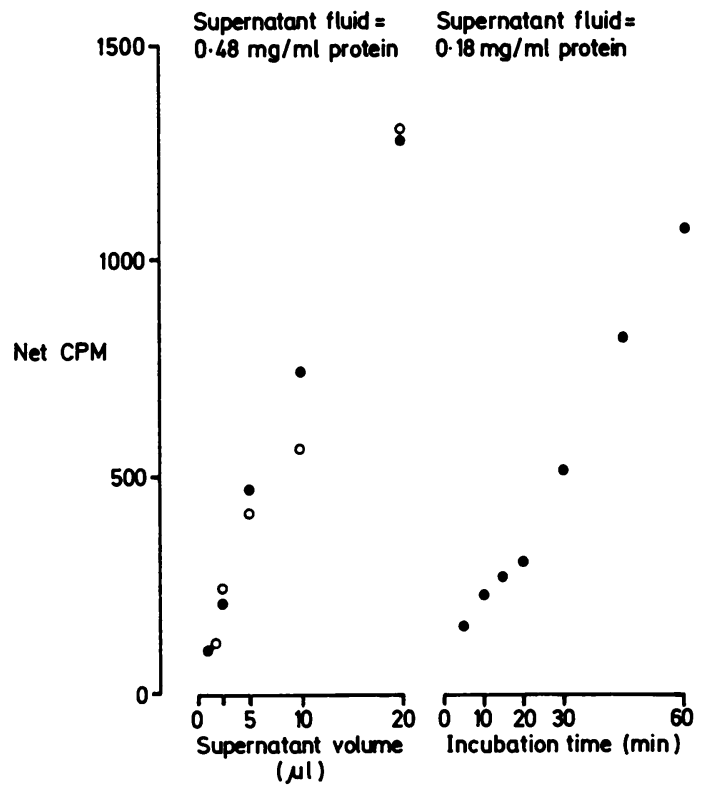

Fig. 1 Linearity of the assay of histamine methyltransferase activity as functions of increasing homogenate volume and incubation time. (O) aminoguanidine, $1 \mathrm{mM}$, was included in the incubation mixture; (O) no aminoguanidine.

STATISTICAL ANALYSIS

Statistical comparison were made using the MannWhitney U test and Spearman's rank correlation test. p Values less than 0.05 were recorded as significant.

\section{Results \\ MUCOSAL HISTAMINE AND HISTAMINE METHYLTRANSFERASE ACTIVITY BEFORE TREATMENT}

Figure 2 shows the gastric histamine values in 'normal' subjects and ulcer patients. In 10 'normal' subjects the median mucosal histamine was 252 $\mathrm{nmol} / \mathrm{g}$ wet weight of the biopsy, (range: 202-457 $\mathrm{nmol} / \mathrm{g}$ ). In 14 patients with duodenal ulcer, the median histamine was $204 \mathrm{nmol} / \mathrm{g}$, (range: 65-298 $\mathrm{nmol} / \mathrm{g}), 19 \%$ lower than in control subjects $(\mathrm{p}<0.05)$.

Figure 3 shows the gastric mucosal histamine methyltransferase values. The median in control subjects was $40 \mathrm{pmol} / \mathrm{mg}$ protein $/ \mathrm{min}$, (range 1864). The median in patients with duodenal ulcer was $49 \mathrm{pmol} / \mathrm{mg}$ protein/min, (range: $22-99$ ), not significantly different from that of the control group.

No significant correlation was observed between gastric histamine and the corresponding histamine 


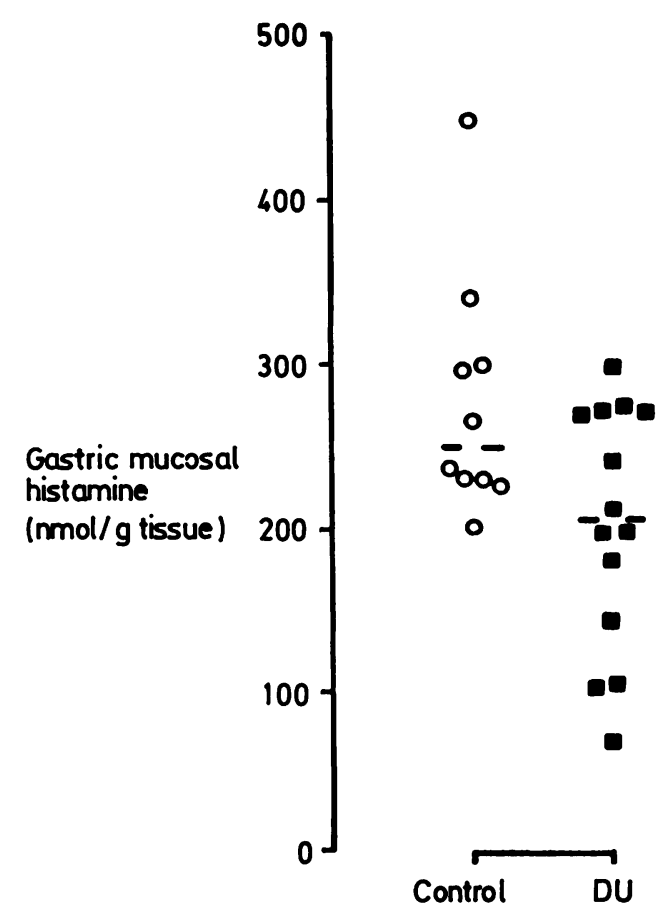

Fig. 2 Gastric mucosal histamine concentration in normal subjects and in patients with duodenal ulcer.

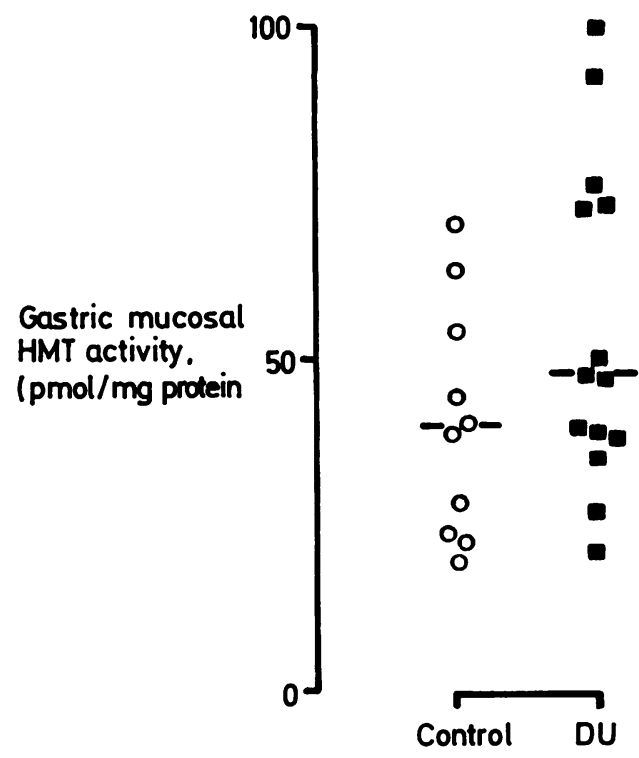

Fig. 3 Gastric mucosal histamine methyltransferase activity in patients with duodenal ulcer and 'normal' subjects. (—) medians NS. methyltransferase activity, either in the 'normal' subjects or in patients with duodenal ulcer.

OMEPRAZOLE, HISTAMINE AND PENTAGASTRIN INDUCED ACID SECRETION

All duodenal ulcers healed after omeprazole therapy.

The results of measurements of gastric mucosal histamine, histamine methyltransferase activity, and of gastric juice acid and histamine are listed in the Table. Figure 4 illustrates the measurements made after omeprazole medication; the results are expressed at a percentage of the pretreatment values.

Comparing values before and after medication in the eight patients, the median post-treatment histamine methyltransferase activity was $105 \%$ (range: 36-380), and the median gastric mucosal histamine was $123 \%$ (range: $56-160$ ). The low dose of omeprazole was associated with an insignificant fall in histamine methyltransferase activity, but the high dose with a significant rise $(p<0.05)$.

During pentagastrin infusion, the median peak

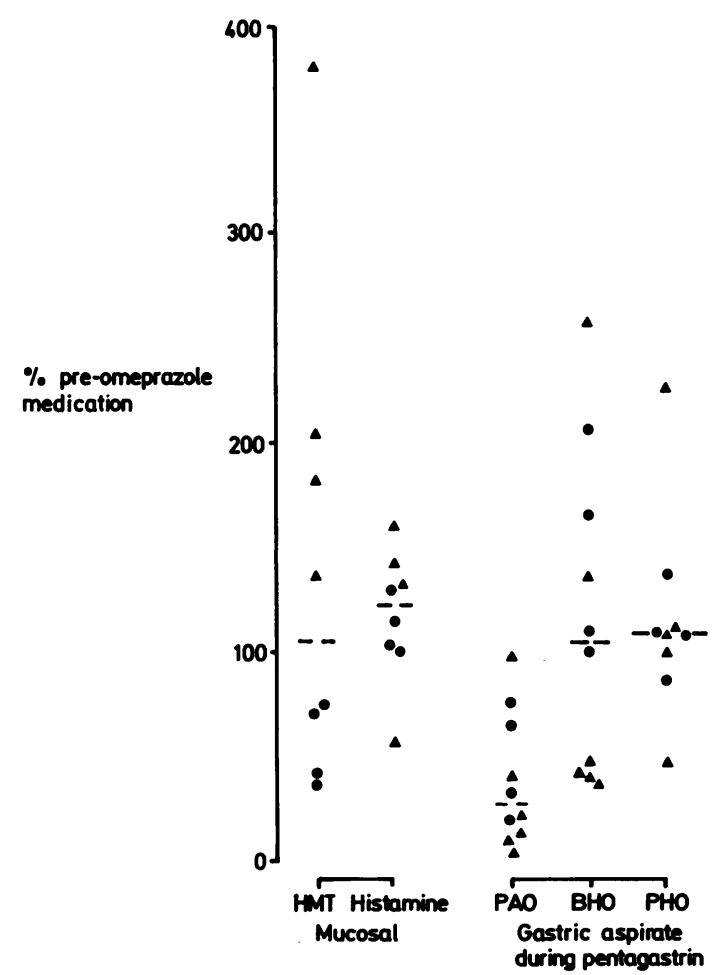

Fig. 4 Changes in mucosal histamine, histamine methyltransferase activity, peak acid output (PAO), basal and peak histamine output $(\mathrm{BHO}, \mathrm{PHO})$ in gastric juice after omeprazole. (O) $20 \mathrm{mg}$; (A) $40 \mathrm{mg}$ daily. 
Table Effect of omeprazole on histamine and pentagastrin stimulated gastric acid secretion

\begin{tabular}{|c|c|c|c|c|c|c|c|c|c|c|c|c|c|}
\hline \multirow[b]{3}{*}{$P t$} & \multirow{3}{*}{$\begin{array}{l}\text { Dose } \\
\text { mg/day }\end{array}$} & \multicolumn{2}{|l|}{$H M T$} & \multicolumn{2}{|c|}{ Mucosal histamine } & \multicolumn{4}{|c|}{ Acid output, nmol/h } & \multicolumn{4}{|c|}{ Histamine output, nmol/h } \\
\hline & & \multirow{2}{*}{$\underset{\text { Pre }}{\text { pmollmg }}$} & \multirow{2}{*}{$\begin{array}{l}\text { protein/min } \\
\text { Post }\end{array}$} & \multirow{2}{*}{$\begin{array}{l}\text { inmollgt } \\
\text { Pre }\end{array}$} & \multirow{2}{*}{$\begin{array}{l}\text { issue } \\
\text { Post }\end{array}$} & \multicolumn{2}{|c|}{ Basal } & \multicolumn{2}{|c|}{ Peak } & \multicolumn{2}{|c|}{ Basal } & \multicolumn{2}{|c|}{ Peak } \\
\hline & & & & & & Pre & Post & Pre & Post & Pre & Post & Pre & Post \\
\hline GD & 20 & $75 \cdot 7$ & $53 \cdot 5$ & 143 & 141 & $1 \cdot 6$ & $0 \cdot 3$ & $55 \cdot 3$ & $35 \cdot 3$ & $2 \cdot 9$ & $4 \cdot 8$ & $8 \cdot 7$ & $12 \cdot 0$ \\
\hline $\mathrm{McW}$ & 20 & $99 \cdot 3$ & $35 \cdot 4$ & 270 & 351 & $1 \cdot 3$ & $5 \cdot 6$ & 29.9 & $22 \cdot 6$ & $7 \cdot 1$ & $7 \cdot 8$ & $8 \cdot 8$ & 9.4 \\
\hline TJ & 20 & - & - & - & - & $7 \cdot 0$ & $0 \cdot 0$ & 65.4 & 12.9 & $2 \cdot 6$ & $2 \cdot 4$ & 30.7 & 33.0 \\
\hline WR & 20 & $38 \cdot 2$ & $15 \cdot 4$ & 105 & 107 & 1.7 & $0 \cdot 0$ & $67 \cdot 0$ & $21 \cdot 6$ & $1 \cdot 5$ & $3 \cdot 1$ & 25.4 & $21 \cdot 8$ \\
\hline AP & 40 & $36 \cdot 3$ & $74 \cdot 1$ & 214 & 343 & $2 \cdot 6$ & $0 \cdot 0$ & $42 \cdot 1$ & $9 \cdot 2$ & $4 \cdot 3$ & $5 \cdot 8$ & 14.9 & 14.9 \\
\hline BA & 40 & 21.9 & $83 \cdot 2$ & 265 & 374 & $8 \cdot 6$ & $0 \cdot 0$ & $68 \cdot 5$ & $1 \cdot 2$ & 7.9 & $2 \cdot 8$ & $15 \cdot 2$ & $16 \cdot 8$ \\
\hline EC & 40 & - & - & - & - & $13 \cdot 8$ & 9.9 & $48 \cdot 6$ & $47 \cdot 1$ & $11 \cdot 7$ & $5 \cdot 5$ & - & $36 \cdot 5$ \\
\hline JW & 40 & $47 \cdot 9$ & $87 \cdot 3$ & 271 & 152 & $10 \cdot 0$ & $0 \cdot 0$ & $63 \cdot 4$ & $7 \cdot 5$ & $1 \cdot 4$ & $3 \cdot 6$ & $11 \cdot 9$ & $26 \cdot 8$ \\
\hline OD & 40 & $39 \cdot 7$ & $54 \cdot 0$ & 65 & 86 & $11 \cdot 6$ & $0 \cdot 0$ & $36 \cdot 7$ & $14 \cdot 5$ & $7 \cdot 0$ & $2 \cdot 8$ & $6 \cdot 6$ & $7 \cdot 2$ \\
\hline RS & 40 & - & - & - & - & $3 \cdot 2$ & $0 \cdot 0$ & $30 \cdot 9$ & $2 \cdot 7$ & $5 \cdot 2$ & $2 \cdot 0$ & $11 \cdot 8$ & $5 \cdot 5$ \\
\hline $\mathbf{S M}^{*}$ & 20 & $47 \cdot 1$ & $34 \cdot 5$ & 269 & 305 & $6 \cdot 1$ & & $40 \cdot 6$ & & $4 \cdot 1$ & & $7 \cdot 1$ & \\
\hline Median & & $43 \cdot 3$ & $53 \cdot 7$ & 239 & 226 & $6 \cdot 1$ & 0.0 & $48 \cdot 6$ & $13 \cdot 7$ & $4 \cdot 3$ & 3.4 & 11.8 & 15.9 \\
\hline
\end{tabular}

* Refused second acid test.

acid output was $27 \%$ of the value before treatment (range: 2-97), with no apparent relationship to dose of omeprazole. The median gastric histamine output assayed in the aspirate during the basal period was 105\% (range: 35-257); and the median peak histamine output was $107 \%$ (range: $47-225$ ).

During secretory tests before omeprazole, the peak histamine output (calculated from the mean of the two highest 10 minute fractions) in the aspirate during pentagastrin infusion was significantly correlated with the peak acid output $(\mathrm{rho}=0.71, \mathrm{p}<0.02)$. No such correlation was found for the corresponding data after omeprazole treatment.

\section{Discussion}

In the present study we have confirmed the finding, reported from several laboratories including ours, ${ }^{1210}$ of significantly lower than normal gastric mucosal histamine in patients with duodenal ulcer. In contrast with the findings of others, we found no significant difference between mucosal histamine methyltransferase activity in ulcer patients and controls, neither could we demonstrate a correlation between mucosal histamine and histamine methyltransferase activity values. This may be because of the small number of patients studied.

The discrepancy between our results and those of others cannot be explained in terms of biopsy handling (prolonged ischaemia time), or by age and sex differences in the groups studied.

We have previously reported that after treatment with the histamine $\mathrm{H}_{2}$ blocker cimetidine gastric mucosal histamine in patients with duodenal ulcer rose to above control values. ${ }^{1}$ Similarly, selective gastric vagotomy significantly increased gastric mucosal histamine in such patients. ${ }^{2}$ The rise in gastric mucosal histamine may be because of the inhibitory effect of the treatments on gastric acid secretion, as histamine is mobilised in the secretion process.

In the present study, we measured gastric mucosal histamine and histamine methyltransferase activity before and after a course of omeprazole. The median histamine rose $23 \%$ after omeprazole. This difference was not statistically significant $(p=0.08)$, perhaps because of the small numbers.

Barth et $a l^{3}$ reported that selective gastric vagotomy raised the activity of gastric mucosal histamine methyltransferase; this may have facilitated inactivation of histamine and so helped to reduce acid secretion. In the present study, the high drug dose (40 mg daily) was associated with a rise in mucosal histamine methyltransferase activity while the low dose $(20 \mathrm{mg}$ daily) resulted in lower histamine methyltransferase activity. There was no significant change overall, however, in the median value of histamine methyltransferase activity after omeprazole. Omeprazole in both doses used is an effective inhibitor of pentagastrin induced acid secretion, with no dose related difference in this small study. We are unable to explain the discrepancy between the high and low dose effects on histamine methyltransferase activity. The rise after 'high dose' is similar to that seen after cimetidine. If this is directly related to blocking acid secretion we would have expected a similar change after 'low dose'.

We have previously investigated the effect of pentagastrin infusion on the amount of acid and histamine assayed in the gastric aspirate in patients with duodenal ulcer and found them closely correlated ${ }^{7}$. After cimetidine blockade, gastric acid fell rapidly but histamine output in gastric aspirate did not change. ${ }^{11}$ We postulated that pentagastrin acts 
directly, by releasing histamine in the gastric mucosa, which, in turn, releases acid from the parietal cells.

In the present study, the correlation between the peak output of acid and that of histamine in the gastric aspirate induced by pentagastrin is again shown in patients with ulcer before treatment but not after therapy. After omeprazole gastric acid fell, but histamine in the gastric aspirate did not change, either in basal or stimulated outputs. This dissociation is compatible with the hypothesis that pentagastrin stimulates acid secretion from parietal cells by releasing histamine.

We thank Mr S K Li, Miss A Browne, and Mr J Barr for skilled technical assistance and Mrs Iris Fisher for typing the manuscript. Financial support and omeprazole were provided by Astra Pharmaceuticals Ltd.

\section{References}

1 Man WK, Saunders JH, Ingoldby CJH, Spencer J. Effect of cimetidine on the amounts of histamine in the gastric mucosa of patients with gastric or duodenal ulcers. Gut 1981; 22: 923-6.

2 Troidl H, Rohdl H, Lorenz W et al. Effect of selective vagotomy on histamine concentration in gastric mucosa of patients with duodenal ulcer. Br J Surg 1978; 65: 10-16.
3 Barth $\mathrm{H}$, Troidl $\mathrm{H}$, Lorenz $\mathrm{W}$ et al. Histamine and peptic ulcer disease: histamine methyl transferase activity in gastric mucosa of control subjects and duodenal ulcer patients before and after surgery. Agents Actions 1977; 6: 75-9.

4 Lorenz W, Troidl H, Rohde $\mathrm{H}$. Histamine, gastric secretion and peptic ulcer disease: an attempt to define special sources of error and problems in clinicalbiochemical trials. In: Creutzfeldt W, ed. Cimetidine. Amsterdam and Oxford: Excerpta Medica, 1978: 6-34.

5 Fellinius E, Berglindh T, Sachs G et al. Substituted benzimidazoles inhibit gastric secretion by locking $\left(\mathrm{H}^{+}+\mathrm{K}^{+}\right)$ATPase. Nature 1981; 290: 159-61.

6 Cooperative study. Omeprazole for duodenal ulceration-tolerance, acid inhibition, endoscopic healing and recurrence. Br Med J 1984; 289: 525-8.

7 Man WK, Saunders JH, Ingoldby CJH, Spencer J. Effect of pentagastrin on histamine output from the stomach in patients with duodenal ulcer. Gut 1981; 22: 916-22.

8 Taylor KM, Snyder SH. Isotopic microassay of histamine, histidine decarboxylase and histamine methyltransferase in brain tissues. $J$ Neurochem 1972; 19: 1343-58.

9 Lowry OH, Rosebrough NJ, Farr AL. Protein measurement with the Folin phenol reagent. J Biol Chem 1951; 127: 182-6.

10 Peden NR, Callachan H, Shepherd DM, Wormsley KG. Gastric mucosal histamine and histamine methyltransferase in patients with duodenal ulcer. Gut 1982; 23: 58-62.

11 Man WK, Ingoldby CJH, Spencer J. Is pentagastrinstimulated acid secretion mediated by histamine? Gut 1984; 25: 965-70. 